\title{
Investigating the underlying causes of SLI: A non-sign repetition test in British Sign Language
}

\author{
CHLOE R. MARSHALL ${ }^{1}$, TANYA DENMARK ${ }^{2}, \&$ GARY MORGAN $^{2,3}$ \\ ${ }^{1}$ Centre for Developmental Language Disorders and Cognitive Neuroscience, Department of Human Communication Science, \\ University College London, UK, ${ }^{2}$ Deafness, Cognition and Language Research Centre, Department of Human \\ Communication Science, University College London, UK, and ${ }^{3}$ Dept. of Language and Communication Science, \\ City University, London, UK
}

\begin{abstract}
There is controversy over the specificity of Specific Language Impairment (SLI), and whether it is caused by a deficit general to cognition or in mechanisms specific to language itself. We argue that evidence to resolve these conflicting positions could come from the study of children who are acquiring sign language and have SLI. Whereas speech is characterized by rapid temporal changes, the phonology of sign languages relies on the integration of visual information that is often produced simultaneously. These differences in the way linguistic information is processed can allow us to investigate whether SLI is caused by a sensory processing deficit, by a deficit specific to language, or by a deficit in phonological short term memory. One marker for SLI in spoken languages is difficulty repeating non-words, particularly those with complex phonological structures. We report on the development of a non-sign repetition task for BSL users, piloted on deaf children, which is sensitive to age. Non-sign items were graded in terms of phonological complexity, and reveal systematic error patterns as a function of that complexity. We conclude by discussing how this test can be used to probe the underlying nature of language impairments.
\end{abstract}

Keywords: Specific language impairment, British Sign Language, non-word repetition, phonology, working memory.

\section{Introduction}

\section{Hypotheses of SLI}

SLI is generally defined as an impairment which is specific to language. SLI children have the necessary precursors for language (e.g., adequate non-verbal skills, no obvious neurological damage, and for spoken languages, no hearing deficit), but nevertheless show significant language delays. The linguistic characteristics of SLI in a range of spoken languages are well documented. SLI has been studied in languages as diverse as English, Spanish, Finnish, Greek, Hebrew, Mandarin and Japanese. Several common patterns emerge, including impairments in vocabulary, morphosyntax (e.g., inflections such as number and person agreement, and tense; function words such as articles and auxiliaries) and syntax (passives, wh-questions, relative clauses) (see Leonard, 1998, for a review).

Theories of SLI differ as to whether they propose that the impairment arises from a more general cognitive processing deficit or whether the deficit is specific to language. There are two issues here: firstly, the specificity of the deficit (whether it affects areas of cognition other than language), and secondly, its origin (whether it originates from a generalized processing impairment, or from an impairment within the linguistic system and/or related systems, (e.g., phonological short term memory). The specificity and the underlying causes of SLI need to be considered against a backdrop of considerable heterogeneity in SLI: it is possible that different subtypes of SLI exist, with variable specificity and different underlying causes (van der Lely, 2005).

The Generalized Slow Processing Deficit (Kail, 1994) claims that the impairment is not specific to language, and that, instead, children with SLI have a generalized impairment that reduces their processing speed. SLI children have been shown to have slower responses than their age-matched peers on a range of tasks, only some of which tap language directly (Kail, 1994). However, data from many studies are problematic for this hypothesis. There is evidence that group comparisons of processing speed between

Correspondence: Chloe R. Marshall, Centre for Developmental Language Disorders and Cognitive Neuroscience, Department of Human Communication Science, University College London, 2, Wakefield Street, London WC1N 1PF, UK. Tel: +44 (0)20 7679 4048. E-mail: c.marshall@ucl.ac.uk 
SLI and their age-matched controls fail to reach significance (Bavin, Wilson, Maruff, \& Sleeman, 2005), that some SLI children in the group show age-appropriate processing speed (Miller, Kail, Leonard, \& Tomblin, 2001), and that there is no relationship between processing speed and language scores (Lahey, Edwards, \& Munson, 2001). We will not discuss the Generalized Slow Processing Deficit further in this paper.

The Auditory Processing Deficit (APD) Hypothesis (Tallal, 2003; Tallal \& Piercy, 1973) claims that the language deficit in SLI stems from difficulties in processing the rapid temporal changes that characterize speech. This deficit impacts most severely on the processing of acoustically non-salient material, such as inflections and function words, which are often short in duration and unstressed. Tallal and her colleagues have shown that children with language impairments have difficulties processing non-speech stimuli that are rapid in duration, and that therapy designed to target short speech sounds by extending their duration can have a positive impact on language skills (Merzenich et al., 1996). Moreover, when connectionist models of language are trained with degraded phonological material that simulates a perceptual deficit, they produce grammatical errors similar to those made by SLI children (Joanisse \& Seidenberg, 2003). Crucially, however, many children diagnosed with SLI do not have auditory processing deficits. Although group effects are reported by many studies, only a minority of children within the group contribute to those effects. A study by van der Lely, Rosen and Adlard (2004) found that some control children, who by definition have normal language skills, also have an APD. Furthermore, van der Lely and her colleagues (2004) found no correlation between the degree of APD and the severity of the language impairment. Certainly there is an overlap between APD and language impairments, but it is not clear that there is a causal relationship between them, and it appears that an APD is neither necessary nor sufficient to cause SLI (see Rosen, 2003, for a discussion).

The Phonological Short Term Memory (PSTM) Hypothesis (Gathercole \& Baddeley, 1990) claims that SLI children's capacity to store verbal material in phonological short term memory is limited compared to typically developing children. This limited capacity impacts on their ability to learn new words and process important grammatical information such as inflections and function words. Many studies have shown a link between short term memory abilities and vocabulary in typically developing children. SLI children, who have poor vocabularies, have poor short term memories as indexed by the number of nonsense words they can repeat correctlyspecifically, as the number of syllables is increased, the proportion of accurate responses declines dramatically (Bishop, North, \& Donlan, 1996; Dollaghan \& Campbell, 1998; Gathercole \&
Baddeley, 1990). However, a recent study shows no evidence that phonological short term memory is predictive of language impairments (Gathercole, Tiffany, Briscoe, Thorn, \& ALSPAC team, 2005). Furthermore, there is evidence that the phonological properties of the material to be encoded, over and above the quantity of material (number of syllables), affect the amount of phonological material that can be retained in short term memory (Dollaghan, Biber, \& Campbell, 1995; Marshall, Ebbels, Harris, \& van der Lely, 2002). For example, Dollaghan et al. found that lexical long term memory information intrudes on non-word repetition accuracy in typically developing children: non-words with stressed syllables that correspond to real words are repeated more accurately than non-words with non-lexical stressed syllables. Marshall et al. found that children with SLI are more likely to make repetition errors when nonwords are structurally complex, i.e. contain complex syllable structure (consonant clusters) and contain unfooted syllables.

There is conflicting evidence over whether the memory limitations in SLI children extend beyond phonological short term memory. Models of shortterm memory identify two components: the phonological loop and the visuo-spatial sketchpad (Baddeley \& Hitch, 1974). These are domain-specific systems: the phonological loop deals with phonological information, and the visuo-spatial sketchpad is concerned with visual and spatial tasks, such as remembering colours and shapes, and the location and speed of objects in space. Bavin et al. (2005) compared children with SLI and age-matched control children on several tasks of visuo-spatial memory and processing. The two groups performed with equivalent accuracy on a visual search task and in a location recall task. The SLI group, however, performed significantly worse on three measures: they were less accurate in recalling patterns, had a shorter spatial span, and were less able to learn to associate a particular pattern with a particular location. However, other studies have shown that English-speaking SLI children do not have problems with short-term visuospatial memory, despite having problems with the phonological loop (Archibald \& Gathercole, 2006, in press; Hoffman \& Gillam, 2004).

Some researchers claim that SLI children's difficulties in comprehending and using certain grammatical material, e.g., inflections and function words, are caused by a deficit that is specific to language (Rice \& Wexler, 1996; Ullman \& Gopnik, 1999; van der Lely \& Ullman, 2001). There are a number of linguistic theories, and they vary as to where they claim the deficit lies in the linguistic system. For example, the Extended Optional Infinitive Hypothesis claims that the syntactic features that mark tense and agreement inflections develop much later than normal (Rice \& Wexler, 1996). According to the Implicit Rules Hypothesis, the deficit is in the use of grammatical features and morphological paradigms, and inflected 
words are either stored with no internal structure, or are created by an explicitly learnt suffixation strategy (Ullman \& Gopnik, 1999).

The Computational Grammatical Complexity (CGC) Hypothesis has been proposed to account for the syntactic, morphological and phonological impairments shown by a particular subgroup of SLI children, the Grammatical SLI subgroup (Marshall, 2004; van der Lely, 2005). The terms "computational" and "grammatical" are used: "computational" because the core components of grammar that rely on the computation of rules (syntax, morphology and phonology) are affected, and "complexity" because the deficit in each component of grammar lies in the formation of complex structural representations. One possibility is that the deficit in G-SLI impacts on the computation of hierarchical structure and thus affects the representation of grammatical complexity.

The field of SLI research appears to have reached an impasse and is in need of a new way forward. We suggest that sign language offers a novel way of teasing causal theories apart (see Morgan, 2005). For example, the APD hypothesis, which claims that that children with SLI find it difficult to process the auditory properties of language, would not even predict the existence of SLI in deaf signing children, although we will return to this point later. On the other hand, linguistic theories of SLI, which stress that the deficit is in dealing with abstract linguistic knowledge that by definition is not tied to any one modality, would predict that SLI would be found in signing children. Similarly, given that sign languages rely on the phonological loop as spoken languages do (Emmorey \& Wilson, 2004), the PSTM hypothesis of SLI predicts that phonological short term memory impairments will affect signing SLI children. However, sign languages also involve visuo-spatial processing, and so investigating SLI in sign languages allows us to investigate how visuo-spatial short term memory might impact on language skills.

\section{SLI in sign languages}

Little is known about whether SLI does indeed exist in sign languages and what forms it might take. However, some deaf children who are learning sign language do have difficulties similar to those described for Specific Language Impairment (SLI) in spoken languages (Morgan, 2005). One example is a recent case study by Morgan, Herman and Woll (in press) of a deaf boy, Paul, aged 5;2, who has been exposed to British Sign Language (BSL) from birth. Paul has significant deficits in comprehension and production of BSL grammar, based on formal assessment and on linguistic analyses of his sign communication in comparison with age-matched unimpaired signers. In a receptive grammatical task Paul has particular difficulty with linguistic forms such as negation, noun-verb distinctions, spatial verbs and classifiers, that encode meanings through morphosyntactic rules. Paul's productive language, assessed from a mixture of spontaneous communication and more formal assessment, is restricted to small sentences made up of only one or two signs and with very limited grammar.

An estimated $7 \%$ of children learning a spoken language have SLI (Tomblin et al., 1997), and we might therefore expect the same incidence for children acquiring a sign language. There is no reason why this figure might not be even higher, as the etiologies of non-hereditary deafness, such as prematurity and perinatal complications, predispose for SLI (Downs, 1995). Certainly signing children whose slow acquisition is causing concern are regularly referred to clinics (Morgan et al., in press).

An added complication is that more than $90 \%$ of deaf children learn sign language after the optimal early period for native language acquisition because they are born into hearing families with little or no knowledge of sign or how to communicate with deaf children (Morgan, 2005). Great care is needed in distinguishing between delayed development due to poor exposure to language versus a linguistic impairment.

We propose that the existence of SLI in signers has important implications for how we understand the underlying causes of SLI. In fact, our research into the nature of SLI in deaf-signing children has two aims: (1) to construct diagnostic tools for BSL development, in order to identify children with an impairment in language acquisition, and (2) to better understand the underlying causes of SLI.

In this paper we concentrate on phonological abilities. This is because phonology is central to many theories of SLI. For the CGC Hypothesis, phonology is part of the grammar, and phonological complexity is predicted to impact, in at least some children with SLI, on linguistic structures that are phonologically complex. For the APD Hypothesis, auditory processing deficits cause impairments in setting up phonological representations, which in turn impact on other areas of language. For the PSTM Hypothesis, limited phonological storage capacity in short term memory impairs the learning of vocabulary, morphosyntax and syntax.

Our starting point is this: we know that non-word repetition tasks are a good diagnostic marker for SLIthey are both sensitive and specific (Conti-Ramsden \& Hesketh, 2003). Whether this is due to a limited phonological short term memory capacity or to a language-specific deficit in creating and retrieving phonological representations is uncertain, as the task taps phonological memory and representations. Nevertheless, at least some children with SLI have difficulties with phonologically complex structures, and non-word repetition tasks can inform us about children's phonological abilities in both SLI and typical development (e.g., Kirk \& Demuth, 2006; Marshall et al., 2002). We therefore created a 
sign-language equivalent to a non-word repetition task - a non-sign repetition task-in order to investigate phonological abilities in signing children and adults, and to determine whether such a task might provide a useful diagnostic test for SLI signing children.

\section{Sign language phonology}

The phonology of sign languages is generally described as containing three main parameters that vary within certain limits and provide phonemic contrasts-handshape, movement and location (e.g., Brentari, 1998; Stokoe, 1960). These terms are fairly self-explanatory. "Handshape" denotes the particular shape that a hand makes in a sign, and handshapes vary in the number of fingers that are selected and how they are flexed or extended. In our analysis of signs there are two classes of movement- "path movements", which involve movement of the hand and arm, and "hand-internal movements" that involve just the fingers. Signs can have either one of these or both types of movement. Most signs are produced in a neutral location in front of the signer, but they can be produced elsewhere, such as at various locations on the face. Signs can occur in minimal pairs that differ either in handshape, movement or location. For example, the BSL signs for YESTERDAY and TOMORROW have the same handshape and starting location, but differ in movement. Both start with the index finger extended (the remaining fingers and thumb make a fist) and touching the side of the face. In YESTERDAY, the hand moves backwards, whereas in TOMORROW it moves forward.

Phonological complexity can be experimentally manipulated in sign languages as it can in spoken languages. Of the various models of sign language phonology that are available, we use Brentari's Prosodic Model, which defines complex phonological structures as having branching structure in their phonological representation (Brentari, 1998, p. 214). Complexity is closely linked to the linguistic notion of markedness, whereby marked variants are acquired later than the unmarked variants, and unmarked variants are substituted for marked variants in acquisition (e.g., Cheek, Cormier, Repp, \& Meier, 2001; Morgan, Stoneham, \& Barrett-Jones, in press). In this paper the terms "markedness" and "complexity" are used interchangeably. Importantly for our purposes, handshape and movement come in unmarked and marked variants. Markedness for handshape is based on the fingers that are selected and the joints that are involved, and is argued to be based on articulatory and perceptual ease (Ann, 1996). Many signs in BSL are two-handed. In some signs the hands form the same handshape and articulate the same movement. If the two hands have different handshapes, then one hand is less active (the non-dominant hand, $\mathrm{H} 2$ ), and has an unmarked handshape. The more active, dominant, hand (H1) can have either a marked or an unmarked handshape (Battison, 1978).

We follow Brentari in designating as "marked" movements that have both a path movement and a hand-internal movement, and are therefore more complex than just a single path or hand-internal movement (Brentari, p. 214). Note that we are not claiming that all path and hand-internal movements are equally complex. For example, curved or circular path movements are more marked than straight movements, but the Prosodic Model offers a useful way of distinguishing between two levels of complexity: a single movement and a "cluster" of two movements.

\section{Manipulating phonological complexity: Predictions for SLI children}

Certain non-word repetition tasks manipulate phonological complexity. For example, the Test of Phonological Structure (TOPhS) for English (van der Lely \& Harris, 1999) contains 96 non-words that vary systematically in terms of syllabic complexity (singleton consonants versus clusters) and metrical complexity (footed versus unfooted syllables). Consonant clusters and unstressed syllables outside the foot are structures that all young, typically developing children find difficult, but SLI children find them particularly so, even when they are in their teens (Marshall et al., 2002). In fact, some Englishspeaking children with SLI perform poorly even on short non-words of one or two syllables when clusters and marked stress patterns (weak-strong stress) are present (Marshall, 2004). As the previous discussion should make clear, we can manipulate phonological complexity in nonsense signs just as we can in spoken non-words. We predict that some signing SLI children will repeat non-signs less accurately than their peers, because their performance is affected to a greater extent by phonological complexity, and this can be interpreted as indicating a deficit at an abstract linguistic level.

What predictions do other theories of SLI make? In its current form, the APD hypothesis is not relevant to sign because it is an auditory theory. However, its claim rests on the SLI child having difficulties with temporal processing, so if sign language has the same rapid temporal properties as speech, then the APD Hypothesis could also be relevant for SLI signers. However, the temporal properties of sign are not the same as those of speech. Because the articulators in sign are bigger than the articulators for speech, their movements are slower. The average number of words per second in running speech is about $4-5$, compared with $2-3$ signs per second for fluent signing (Bellugi \& Fischer, 1972; Emmorey, 2002). Moreover, sign languages prefer to order linguistic information spatially and non-sequentially. For example, non-concatenative morphology is more frequent than linear affixation, 
syntactic markers are often conveyed by facial expressions that are produced simultaneously with manual signs, and phonological distinctions tend to be simultaneous rather than sequential.

The evidence for phonological working memory deficits in SLI comes from performance on nonwords where the number of syllables exceeds three (Gathercole \& Baddelely, 1990)—when the number of syllables is higher, SLI performance is particularly poor compared to typically developing age-matched peers. The notion of the syllable in sign languages is controversial. It is accepted that spoken language syllables revolve around a nucleus, which is the peak of sonority. Relative sonority is defined in terms of perceptual salience (i.e., loudness) of sound segments. Many researchers agree that for signs, movement constitutes the most salient part, and could therefore be taken to represent the "sonority peak" of a syllable (e.g., Brentari, 1990; Corina, 1990). So can we construct a non-sign test that stresses phonological memory capacity as well as the encoding/retrieval of phonological representations? Unfortunately it is not possible to manipulate the number of syllables in a non-sign: signs in BSL are maximally bisyllabic, but the majority are in fact monosyllabic. We will discuss the implications of this limitation to our task in the discussion section. Of importance is the fact that the PSTM hypothesis would not predict differences between SLI and control children on one and two syllable forms.

In sum, investigating language impairments in sign languages alongside spoken languages might allow us to tease apart different theories of SLI. We stress that this is a preliminary study. Very few non-sign tasks have been devised previously (e.g., Marshall, Atkinson, Woll, \& Thacker, 2005). As the methodology is relatively new we piloted the test with a small group of deaf children (15) in order to determine whether this task merits refinement and standardization on a larger group of deaf children who are acquiring BSL as a natural first language, before it is used with language-impaired signers. We are concerned in this preliminary study with determining whether deaf children's performance on this task:

- shows an effect of development,

- shows an effect of phonological complexity,

- can be scored reliably.

\section{Method}

\section{Procedure}

In creating nonsense signs for the repetition test we manipulated phonological complexity as shown in Table I. Complexity of handshapes and movements were manipulated orthogonally. Simple handshapes were defined as having an unmarked dominant handshape $(\mathrm{H} 1)$, while complex handshapes had a marked dominant handshape. All signs were two-handed. Simple movements had either a hand-internal or a path movement, and complex movements had both hand-internal and path movements. We chose not to include location as a variable, because the acquisition of this parameter is subject to fewer errors than that of handshape and movement (Cheek et al., 2001; Morgan et al., in press). The majority of our signs were executed in the neutral location. Non-signs were created by a Deaf native-signing informant, and 12 were chosen for each condition. Crucially, all were possible signs in BSL, just not actual lexical items, and this was confirmed by our informant, who is familiar with several regional dialects of BSL.

Using a digital video camera, we recorded our informant producing 48 experimental signs and three practice signs, ensuring that her upper torso and face were in the centre of the picture. We subsequently edited the items into a test sequence. Before each sign the viewer saw a smiley face cartoon in the middle of the screen which acted as a focus point. The viewer then saw the nonsense sign, and the screen went blank for 4 seconds, during which the viewer repeated the sign. Halfway through the test a short and motivating animated cartoon was played, in order to give the viewer a short break. The entire test lasted 10 minutes (see Figure 1). Viewers' responses were video-taped, and then transcribed by the second author, who is bilingual in BSL and English (hearing native signer), in consultation with the other two authors and our informant.

\section{Participants}

A group of 15 deaf children, aged between 4 and 10 years, and all exposed to sign early and acquiring sign in a bilingual BSL/English primary school from fluent deaf and hearing adults, took part in this study. None of the deaf children had any developmental

Table I. Non-sign stimuli.

\begin{tabular}{lll}
\hline & & Handshape \\
\cline { 2 - 3 } $\begin{array}{l}\text { Movement } \\
\text { Simple }\end{array}$ & Simple & Complex \\
& 1 movement (either hand-internal or path) & H1 marked. \\
& (0 degrees of complexity) & (1 degree of complexity) \\
Complex & H1 unmarked. & H1 marked. \\
& 2 movements (hand-internal and path) & 2 movements (hand-internal and path) \\
& (1 degree of complexity) & (2 degrees of complexity)
\end{tabular}


impairments beyond their deafness. Details of the group are presented in Table II.

\section{Analysis}

Scoring responses to a task such as this one is not straightforward. Our aims were to devise an error classification scheme that allowed us to record just those errors that indicated a phonemic error and the types of phonological errors that are observed in acquisition (e.g., the sequential production of a path movement and a hand-internal movement that should be produced simultaneously). We did not want to record errors such as, for example, unusually slow or fast rates of movement, which are phonetic rather than phonological (for a detailed discussion of phonological and phonetic errors in sign language, see Brentari, Poizner, \& Kegl, 1995). To illustrate the difference between phonemically contrastive and non-contrastive errors, consider some examples from English. If a child repeats a nonsense word "snid" as "nid" or "snit", these errors are phonemically contrastive, just like the real word "trod" being repeated as "rod" or "trot". If, on the other hand, the child repeats "snid" as "sssnid", prolonging the "s", or said "snid" unusually fast, these errors are not phonemically contrastive-"tttrod", with a prolonged " $t$ ", or a very fast "trod" are still interpreted as the lexical item "trod".

Based on an initial examination of the data, we devised a scheme that characterized errors in the two phonological parameters of handshape and movement (which itself consists of two types of movements: hand-internal and path). The error classification scheme that we used is set out in Table III.

Two types of handshape errors occurred. The first was where the child used the wrong handshape, for example an unmarked handshape instead of a marked handshape, or a handshape not used in BSL. The second was where sign mimicked the stimulus but was produced with only one hand instead of two. There were also two types of errors on hand-internal movements. On occasion the handinternal movement was altered-most frequently the hand-internal movement present in the stimulus was deleted, or a hand-internal movement was produced

\section{Practice items from the pilot version of the non-sign repetition test. Each item was preceded by a smiley face indicating the child should look at the screen and followed by a black screen which was the cue for the child to repeat the sign.}

Figure 1. Short video of non-sign repetition test. Download video from: www.tandf.co.uk/journals/titles/14417049.asp volume 8, number 4, December 2006. despite not being present in the stimulus. The other error type was where the stimulus had internal movement simultaneous to the path movement (e.g., a forward path movement whilst fingers were flicking throughout), but the signer produced them sequentially (e.g., by first flicking the fingers and then producing the path movement).

Several types of errors were observed for path movements. On occasion the direction of movement was wrong, or reversed (e.g., the stimulus had a forward movement whereas the signer produced it with a backward movement). On occasion, in signs which required contact either between two hands,

Table II. Deaf child participants (ni= no information).

\begin{tabular}{|c|c|c|c|c|c|c|}
\hline $\begin{array}{l}\text { Participant } \\
\text { Code }\end{array}$ & Age & Sex & $\begin{array}{c}\text { Deaf/ } \\
\text { Hearing }\end{array}$ & $\begin{array}{l}\text { Parents } \\
\text { deaf/ } \\
\text { hearing }\end{array}$ & $\begin{array}{l}\text { Born } \\
\text { deaf? }\end{array}$ & $\begin{array}{c}\text { Age } \\
\text { started } \\
\text { signing }\end{array}$ \\
\hline $\mathrm{DC} 1 \mathrm{~K}$ & 10 & M & Deaf & Deaf & ni & $\mathrm{ni}$ \\
\hline DC2S & 10 & $M$ & Deaf & Deaf & yes & 2 \\
\hline $\mathrm{DC} 3 \mathrm{H}$ & 8 & $\mathrm{~F}$ & Deaf & Hearing & yes & 3 \\
\hline DC4R & 8 & $\mathrm{~F}$ & Deaf & Deaf & yes & 2 \\
\hline DC5K & 8 & $M$ & Deaf & $\mathrm{ni}$ & ni & ni \\
\hline DC6R & 8 & $\mathrm{~F}$ & Deaf & Deaf & yes & 0 \\
\hline DC7S & 7 & M & Deaf & Deaf & yes & 2 \\
\hline DC8B & 7 & $M$ & Deaf & Hearing & yes & 2 \\
\hline DC9S & 7 & $M$ & Deaf & Hearing & no & 3 \\
\hline DC10S & 7 & M & Deaf & Hearing & yes & 3 \\
\hline DC11J & 7 & $M$ & Deaf & Deaf & yes & ni \\
\hline DC12A & 6 & M & Deaf & Hearing & yes & 3 \\
\hline DC13J & 4 & $M$ & Deaf & Deaf & yes & 2 \\
\hline DC14L & 4 & $\mathrm{~F}$ & Deaf & Hearing & no & ni \\
\hline DC15R & 4 & $\mathrm{~F}$ & Deaf & Deaf & yes & ni \\
\hline
\end{tabular}

Table III. Error types.

\begin{tabular}{ll}
\hline Parameter & Error \\
\hline Handshape & WH - Wrong handshape produced. \\
$1 \mathrm{H}-$ Sign is produced one-handed \\
instead of two-handed. \\
MICH - Movement changed, so there is \\
omission of an internal movement, or \\
addition of an internal movement. \\
MS - Separation of hand-internal and \\
hand-internal \\
path movements where one movement \\
is done and then the other instead of \\
both at the same time. \\
WP - Wrong path, so there is no path or \\
path is added when it shouldn't be. \\
RD - Reverse direction, i.e., movement is \\
going in the wrong direction. \\
NC - No contact when hands are \\
supposed to contact each other and \\
don't. \\
AC - Added contact when hands contact \\
when they are not supposed to. \\
R - Repetition error, i.e., addition of an \\
extra movement, or deletion of a \\
repeated movement.
\end{tabular}

Note: Each non-sign was scored as follows. Participants had the potential to get a score of 3 for each sign, with a point for handshape, internal movement and path movement, if they got those aspects of the sign correct. If the child made one or more errors within each category, he/she was awarded a score of 0 for that category. 
or one hand and a different part of the body, the contact was omitted. The reverse of this error was when contact was made between two hands or between one hand and another part of the body, despite not being present in the stimulus. Finally, we coded repetition errors where there was a reduction in the number of times a path movement should be repeated, for example a repetition of a movement only once or twice instead of three times, or alternatively a movement was repeated where it should not have been. Many of these handshape and movement errors have been previously identified in the acquizition of British and American sign languages (Cheek et al., 2001; Morgan, 2006; Morgan et al., in press).

In order to calculate inter-coder reliability, data from four children were transcribed by a fluent signer who had not been involved in the construction of the test. Agreement between this new coder's transcriptions and the second author's transcriptions was $93 \%$ for handshape, $97.5 \%$ for path movement and $93.75 \%$ for hand-internal movement, which compares favourably with spoken non-word repetition tests (e.g., 94\% for English non-words, Dollaghan \& Campbell, 1998; 93\% for Swedish non-words, Reuterskiold-Wagner, Sahlen, \& Nyman, 2005).

\section{Results}

The percentage total correct score for each participant was calculated, based on the sum of that participant's accurate repetition of handshape, handinternal movement and path movement. All children completed all 48 test items. The scores are presented in Figure 2.

Performance accuracy ranged between $47 \%$ and $90 \%$. There was a very strong correlation between age and performance in this group, $r=.806$, $\mathrm{p}<.001$, with age accounting for $65 \%$ of the variance in scores. In order to investigate the effect of complexity on performance, we compared response accuracy for non-signs with 0,1 or 2 levels of complexity (see Table I). Responses reveal

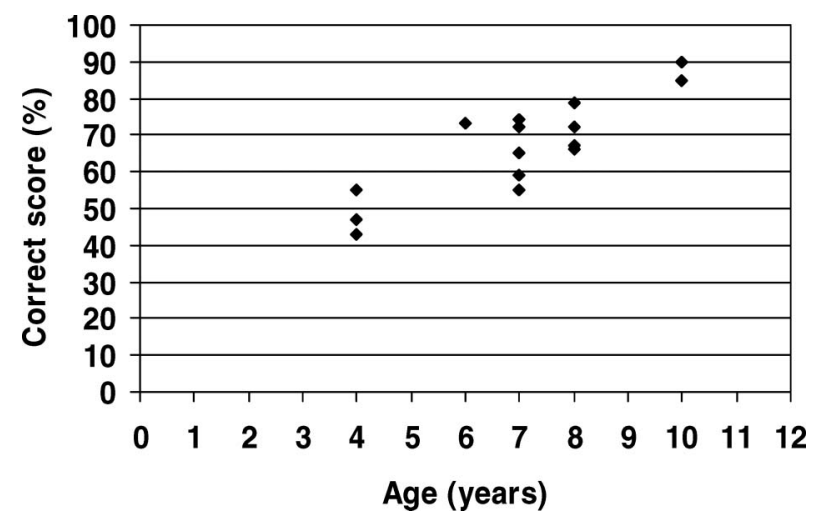

Figure 2. Repetition accuracy. systematic increase in errors as a function of phonological complexity, with a significant correlation between complexity and performance, $\mathrm{r}=-.421, \mathrm{p}=.003$ (see Figure 3).

\section{Discussion}

In this paper we report on the development of a nonsign repetition task for BSL signers. Our work was motivated by two aims: (1) to construct diagnostic tools for BSL development (2) to better understand the underlying causes of SLI. Our nonsense signs were phonologically possible signs in BSL, but not actual lexical items. We manipulated phonological complexity by systematically varying handshape (marked and unmarked) and movement (handinternal or path versus hand-internal and path).

We presented pilot data from a group of deaf children who have had early exposure to BSL. Although the data are preliminary, they reveal a strong correlation between age and repetition accuracy, and an effect of phonological complexity, indicating that the test indexes phonological development. Furthermore, we have devised a reliable coding scheme for errors. With inter-coder reliability at between 93 and $97.5 \%$, we are confident that the test is relatively easy to score, and this point is essential if the study is to be developed and widely used.

The first aim of constructing the non-sign repetition test is to develop a diagnostic test for language impairments in BSL. On the basis of these pilot data we are refining the test. For example, we are concerned that at 10 minutes it might be too long for the youngest children-the 4-year-olds-so we are reducing the number of stimuli to 40 from the current 48 . We are also taking care to balance particular handshapes, path movements and handinternal movements across conditions. We will standardize the revised version on a large population of deaf native-signing children and will collect control phonetic data from hearing non-signing children of the same age. We will then test it on children whose acquisition of BSL is causing concern

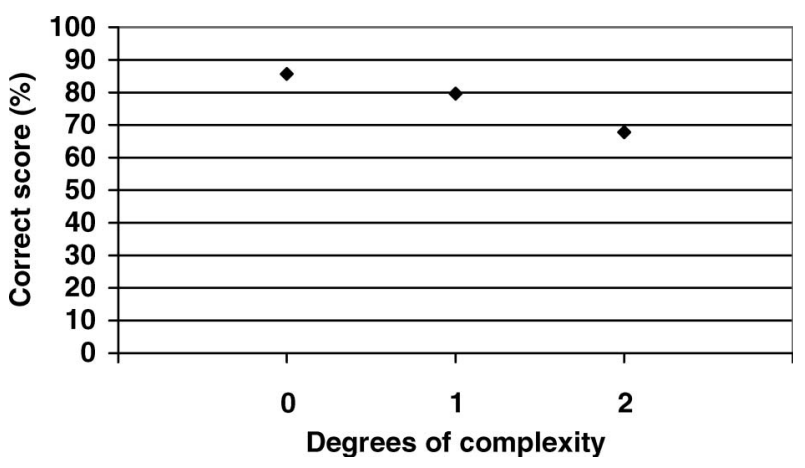

Figure 3. Repetition accuracy according to degrees of phonological complexity. 
as reported by trained speech and language therapists and indicated by standardized tests of other BSL language skills. If those children whose language is causing concern do perform poorly on the test, then this would indicate its potential as a good diagnostic marker. Similarly, for deaf children in the standardization sample who perform at the low end on the test, we will investigate their more general BSL abilities, using both receptive and productive tasks (Herman et al., 2004; Herman, Holmes \& Woll, 1999). If their language abilities are also weak, then this further indicates that the test has use in the diagnosis of language impairments.

The second aim of constructing the non-sign repetition test is to explore the underlying causes of SLI, an issue of great controversy in the field of language impairments (Bishop, North, \& Donlan, 1996; Gathercole \& Baddeley, 1990; Joanisse \& Seidenberg, 2003; Kail, 1994; Rosen, 2003; Tallal, 2003; van der Lely, 2005). Given the slowness of sign compared to speech, and its characteristic simultaneous rather than sequential processing, we believe that the auditory/ rapid temporal processing theory of SLI will be unable to explain cases of SLI in sign languages, and poor performance on our test. We will investigate whether there is a link between visual memory capacity, phonological memory capacity (as indexed by digit span task), performance on the non-sign repetition task and performance on other measures of language abilities. This will serve to elucidate the relationship between working memory and language abilities in both typically developing and SLI deaf children. And finally, if SLI signers find it particularly difficult to repeat phonologically complex non-signs, this would lend support to theories of SLI that stress the role of linguistic complexity in the underlying deficit. At the very least, models of language acquisition and of developmental language disorders need to be able to account for data from sign languages. Because of the dramatic differences between the spoken and signed modalities, studying SLI in sign languages offers a novel way of testing hypotheses of SLI and further developing these models.

\section{Acknowledgements}

We thank our research assistant Cathie Green, and the staff and children at Frank Barnes School for Deaf children, London. The British Academy and the Latsis Foundation generously awarded travel grants to $\mathrm{CM}$ so that we could present this work at the Latsis Conference on Early Language Development and Disorders in Geneva, and we thank the conference audience for their feedback. We thank two anonymous reviewers for their careful reading of a previous draft, and their detailed and expert comments. We gratefully acknowledge the award to GM of a City University pump-priming grant, and the support of the Economic and
Research Council of Great Britain (RES-620-286001), Deafness, Cognition and Language Research Centre.

\section{References}

Ann, J. (1996). On the relation between ease of articulation and frequency of occurrence of handshapes in two sign languages. Lingua, 98, 19-41.

Archibald, L., \& Gathercole, S. (2006). Visuo-spatial immediate memory in Specific Language Impairment. Fournal of Speech, Language, and Hearing Research, 49, 265-277.

Archibald, L., \& Gathercole, S. (in press). Short-term and working memory in Specific Language Impairment. International Fournal of Communication Disorders.

Baddeley, A. D., \& Hitch, G. (1974). Working memory. In G. Bower (Ed.), The psychology of learning and motivation, Volume 8 (pp. 47-90). New York: Academic Press.

Battison, R. (1978). Lexical borrowing in American Sign Language. Silver Spring, MD: Linstok Press.

Bavin, E., Wilson, P., Maruff, P., \& Sleeman, F. (2005). Spatiovisual memory of children with specific language impairment: evidence for generalized processing problems. International Fournal of Language and Communication Disorders, 40, $319-332$.

Bellugi, U., \& Fischer, S. (1972). A comparison of sign language and spoken language. Cognition, 1, 173-200.

Bishop, D., North, T., \& Donlan, C. (1996). Non-word repetition as a behavioural marker for inherited language impairment: Evidence from a twin study. Fournal of Child Psychology and Psychiatry, 37, 391-403.

Brentari, D. (1990). Theoretical foundations of American Sign Language. Unpublished $\mathrm{PhD}$ dissertation, University of Chicago., IL.

Brentari, D. (1998). A prosodic model of sign language phonology. Cambridge, MA: MIT Press.

Brentari, D., Poizner, H., \& Kegl, J. (1995). Aphasic and Parkinsonian signing: differences in phonological disruption. Brain and Language, 48, 69-105.

Cheek, A., Cormier, K., Repp, A., \& Meier, R. (2001). Prelinguistic gesture predicts mastery and error in the production of early signs. Language, 77, 292-323.

Conti-Ramsden, G., \& Hesketh, A. (2003). Risk markers for SLI: a study of young language-learning children. International fournal of Language and Communication Disorders, 38, 251-253.

Corina, D. (1990). Reassessing the role of sonority in syllable structure: evidence from a visual-gestural language. Papers from the Chicago Lingusitics Society, 26, 33-44.

Dollaghan, C., \& Campbell, T. (1998). Non-word repetition and child language impairment. Fournal of Speech, Language, and Hearing Research, 41, 1136-1146.

Dollaghan, C., Biber, M., \& Campbell, T. (1995). Lexical influences on non-word repetition. Applied Psycholinguistics, $16,211-222$.

Downs, M. P. (1995). Universal newborn hearing screening: The Colorado story. International fournal of Pediatric Otorhinolaryngology, 32, 257-299.

Emmorey, K., \& Wilson, M. (2004). The puzzle of working memory for sign language. Trends in Cognitive Sciences, 8, $521-523$.

Emmorey, K. (2002). Language, cognition and the brain: Insights from sign language research. Mahwah, NJ: Lawrence Erlbaum Associates.

Gathercole, S., \& Baddeley, A. (1990). Phonological memory deficits in language disordered children: is there a causal connection? Fournal of Memory and Language, 29, 336-360.

Gathercole, S., Tiffany, C., Briscoe, J., Thorn, A., \& ALSPAC team (2005). Developmental consequences of phonological loop deficits during early childhood: A longitudinal study. fournal of Child Psychology and Psychiatry, 46, 598-611. 
Herman, R., Grove, N., Holmes, S., Morgan, G., Sutherland, H., \& Woll, B. (2004). Assessing British Sign Language Development: Production Test: Narrative Skills. London: City University.

Herman, R., Holmes, S., \& Woll, B. (1999). Assessing British Sign Language Development: Receptive Skills Test. Gloucestershire: Forest Bookshop.

Hoffman, L., \& Gillam, R. (2004). Verbal and spatial information processing constraints on children with Specific Language Impairment. Fournal of Speech and Hearing Research, 47, $114-125$.

Joanisse, M., \& Seidenberg, M. (2003). Phonology and syntax in Specific Language Impairment: Evidence from a connectionist model. Brain and Language, 86, 40-56.

Kail, R. (1994). A method for studying the generalized slowing hypothesis in children with Specific Language Impairment. fournal of Speech and Hearing Research, 37, 418-421.

Kirk, C., \& Demuth, K. (2006). Accounting for variability in 2-year-olds' production of coda consonants. Language Learning and Development, 2, 97-118.

Lahey, M., Edwards, J., \& Munson, B. (2001). Is processing speed related to severity of language impairment? fournal of Speech, Language, and Hearing Research, 44, 1354-1361.

Leonard, L. (1998). Children with Specific Language Impairment. Cambridge, MA: MIT Press.

Marshall, C. R. (2004). The morpho-phonological interface in Specific Language Impairment. Unpublished $\mathrm{PhD}$ dissertation, University of London.

Marshall, C. R., Ebbels, S., Harris, J., \& van der Lely, H. (2002). Investigating the impact of prosodic complexity on the speech of children with Specific Language Impairment. In $\mathrm{R}$. Vermeulen \& A. Neeleman (Eds.), UCL Working Papers in Linguistics, 14, 43-66.

Marshall, J., Atkinson, J. R., Woll, B., \& Thacker, A. (2005). Aphasia in a bilingual user of British Sign Language and English: Effects of cross linguistic cues. Fournal of Cognitive Neuropsychology, 22, 719-736.

Merzenich, M., Jenkins, W., Johnston, P., Schreiner, C., Miller, S., \& Tallal, P. (1996). Temporal processing deficits of language-learning impaired children ameliorated by training. Science, 271, 77-81.

Miller, C., Kail, R., Leonard, L., \& Tomblin, J. B. (2001). Speed of processing in children with Specific Language Impairment. fournal of Speech, Language, and Hearing Research, 44, $416-433$.

Morgan, G. (2005). Biology and behaviour: Insights from the acquisition of sign language. In A. Cutler (Ed.), Twenty-first century psycholinguistics: Four cornerstones (pp. 191-208). Mahwah, NJ: Lawrence Erlbaum.

Morgan, G. (2006). Children are just lingual: The development of phonology in British Sign Language. Lingua, 116, 1507-1523.
Morgan, G., Herman, R., \& Woll, B. (in press). Language impairments in sign language: Breakthroughs and puzzles. International fournal of Language and Communication Disorders.

Morgan, G., Stoneham, H., \& Barrett-Jones, S. (in press). Universals in phonological development: Insights from the acquisition of sign language. Applied Psycholinguistics.

Reuterskiold-Wagner, C., Sahlen, B., \& Nyman, A. (2005). Non-word repetition and non-word discrimination in Swedish preschool children. Clinical Linguistics and Phonetics, 19, 681-699.

Rice, M., \& Wexler, K. (1996). Towards tense as a clinical marker of specific language impairment in English-speaking children. Fournal of Speech and Hearing Research, 39, 1239-1257.

Rosen, S. (2003). Auditory processing in dyslexia and specific language impairment: is there a deficit? What is its nature? Does it explain anything? fournal of Phonetics, 31, 509-527.

Stokoe, W. C. (1960). Sign language structure: An outline of the visual communication system of the American deaf. Studies in Linguistics Occasional Papers 8. University of Buffalo [Revised 1978 Linstok Press].

Tallal, P., \& Piercy, M. (1973). Defects of non-verbal auditory perception in children with developmental aphasia. Nature, $241,468-469$.

Tallal, P. (2003). Language learning disabilities: integrating research approaches. Current Directions in Psychological Science, $12,206-211$.

Tomblin, B., Records, N., Buckwalter, P., Zhang, X., Smith, E., \& O’Brien, M. (1997). Prevalence of Specific Language Impairment in kindergarten children. Fournal of Speech, Language, and Hearing Research, 40, 1245-1260.

Ullman, M., \& Gopnik, M. (1999). Inflectional morphology in a family with inherited SLI. Applied Psycholinguistics, 20, 51-117.

van der Lely, H. K. J. (2005). Domain-specific cognitive systems: Insight from Grammatical specific language impairment. Trends in Cognitive Sciences, 9, 53-59.

van der Lely, H. K. J., \& Harris, J. (1999). Test of Phonological Structure. Available from the first author at the Centre for Developmental Language Disorders and Cognitive Neuroscience, University College London.

van der Lely, H. K. J., \& Ullman, M. (2001). Past tense morphology in specifically language-impaired and normally developing children. Language and Cognitive Processes, 16, $177-217$.

van der Lely, H. K. J., Rosen, S., \& Adlard, A. (2004). Grammatical language impairment and the specificity of cognitive domains: relations between auditory and language abilities. Cognition, 94, 167-183. 